\title{
Boar sperm cryosurvival is better after exposure to seminal plasma from selected fractions than to those from entire ejaculate
}

Diego V. Alkmin, Cristina Perez-Patino, Isabel Barranco, Inmaculada Parrilla, Juan M.

Vazquez, Emilio A. Martinez, Heriberto Rodriguez-Martinez and Jordi Roca

\section{Linköping University Post Print}

\section{Tweet}

N.B.: When citing this work, cite the original article.

Original Publication:

Diego V. Alkmin, Cristina Perez-Patino, Isabel Barranco, Inmaculada Parrilla, Juan M. Vazquez, Emilio A. Martinez, Heriberto Rodriguez-Martinez and Jordi Roca, Boar sperm cryosurvival is better after exposure to seminal plasma from selected fractions than to those from entire ejaculate, 2014, Cryobiology, (69), 2, 203-210.

http://dx.doi.org/10.1016/j.cryobio1.2014.07.004

Copyright: Elsevier

http://www.elsevier.com/

Postprint available at: Linköping University Electronic Press

http://urn.kb.se/resolve?urn=urn:nbn:se:liu:diva-111747 
Boar sperm cryosurvival is better after exposure to seminal plasma from selected fractions than to those from entire ejaculate

Diego V. Alkmin ${ }^{1}$, Cristina Perez-Patiño ${ }^{1}$, Isabel Barranco ${ }^{1}$, Inmaculada Parrilla ${ }^{1}$, Juan M. Vazquez ${ }^{1}$, Emilio A. Martinez ${ }^{1}$, Heriberto Rodriguez-Martinez ${ }^{2}$, Jordi Roca ${ }^{1 *}$

${ }^{1}$ Department of Medicine and Animal Surgery, University of Murcia, Murcia, Spain.

${ }^{2}$ Department of Clinical \& Experimental Medicine (IKE), University of Linköping, Linköping, SE-581 85, Sweden

*Corresponding author: Jordi Roca. Department of Medicine and Animal Surgery, Faculty of Veterinary Science. University of Murcia, E-30100 Murcia, Spain. Phone: +34 868 884735; Fax: +34 868 887069; e-mail: roca@um.es 


\section{Abstract}

Boar bulk ejaculates are now being collected instead of usual sperm-rich fractions (SRF) for artificial insemination purpose. The present study evaluated the influence of holding boar sperm samples before freezing surrounded in their own seminal plasma (SP), from either fractions/portions or the entire ejaculate, on post-thawing sperm quality and functionality. Ejaculates collected as bulk (BE) or as separate (first $10 \mathrm{~mL}$ of SRF [P1] and rest of SRF [P2]) from 10 boars were held $24 \mathrm{~h}$ at $15-17^{\circ} \mathrm{C}$ and then frozen. Some bulk ejaculate samples were frozen immediately after collections as Control. In addition, epididymal sperm samples from the same 10 boars were collected post-mortem and extended in SP from P1 (EP1), P2 (EP2) and post SRF (EP3), and also held 24 h before freezing for a better understanding of the influence of SP on boar sperm cryopreservation. The sperm quality (motility, evaluated by CASA, and viability, evaluated by flow cytometry) and functionality (flow cytometry assessment of plasma membrane fluidity, mitochondrial membrane potential and intracellular generation of reactive oxygen species [ROS] in viable sperm) were evaluated at 30, 150 and 300 min post-thaw. Post-thawing sperm quality and functionality of P1 and P2 were similar but higher $(\mathrm{p}<0.01)$ than BE samples. Control samples showed higher $(\mathrm{p}<0.01)$ post-thaw sperm quality and functionality than BE samples. Post-thawing sperm quality and functionality of EP1 and EP2 were similar but higher $(\mathrm{p}<0.05)$ than EP3. These results showed that boar sperm from $\mathrm{BE}$ are more cryosensitive than those from the SRF, particularly when held $24 \mathrm{~h}$ before freezing, which would be attributable to the cryonegative effects exerted by the SP from post SRF.

Keywords: Ejaculate, epididymis, sperm, seminal plasma, porcine. 


\section{Introduction}

Frozen-thawed (FT) boar sperm, other than the routinely used liquid-stored (LS), should be used in artificial insemination (AI) programs, given their additional benefits regarding biosecurity, international exchange and genetic improvement [29]. Despite these primary compelling benefits, FT-sperm is not yet widely used owing to its still notorious low cryosurvival and the short lifespan depicted by the sperm cryosurviving [26]. Therefore, research is still pursuing alternative ways to increase sperm cryosurvival.

Customary removal of the seminal plasma (SP) before freezing, in order to concentrate sperm for further extension in cooling and freezing extenders, has motivated alternative studies aiming to elucidate the role of native SP on boar sperm freezability. Despite many studies has attempted to tackle its role over the recent years, the topic is still pending, since results had been inconclusive [8]. It is, however, widely accepted that holding sperm suspended in their own native SP prior to cooling improves sperm resistance to cold shock $[18,24]$. Consequently, such procedure is praxis in conventional cryopreservation protocols, albeit there are substantial differences regarding either the duration of the SPexposure $[11,15,31,35,36]$ or the evidence of its effectiveness on sperm freezability. Some authors reported that SP-exposure improves it [37], while others found that its influence is inconsequent or even detrimental [12,21]. One explanation for these divergent results would be the lack of agreement among studies for the origin and characteristics of the SP surrounding the sperm used for the testing. The boar ejaculate is expelled in rather easily identifiable fractions, each one of these containing varying sperm numbers (or even their absence) but, as importantly, different composition of the SP. The SP composition and volume follows a differential secretion of accessory glands, and the differential presence of epididymal fluid [29]. Thus, unless the ejaculate is collected in one single container, marking its classical large volume and low sperm numbers per mL; 
when fractions are collected they show clear differences among a sperm-rich fraction (SRF) and the following sperm-poor fraction, the so-called post-sperm-rich fraction (PSRF). With practice during sperm collection, portions of these can also be collected as for instance the sperm-peak portion [29]. While sperm numbers present defines these fractions, differences are also clear between fractions for the SP, particularly regarding its protein contents [30].

The traditional glove hand method used for manual ejaculate collection in pigs allows for easy sampling of different fractions or even portions within fractions. The SRF is usually the only fraction collected for freezing $[9,17,18]$, although some cryopreservation protocols contemplate the entire ejaculation $[4,14,27]$. In contrast, other studies suggest only freezing the first $10 \mathrm{~mL}$ of the SRF, the sperm-peak portion because the SP of this portion seems to have a greater cryoprotective effect $[29,32]$. Although these results would prove to the SP surrounding sperm at ejaculation influences boar sperm freezability, it remains unclear the magnitude of this influence, which could depend of fractions/portions of the ejaculate. The main purpose of this study is clarifying this issue. Clarifying this issue is particularly relevant today because, for productivity and hygienic reasons, semi-automatic systems, such as Collectis ${ }^{\circledR}[2]$, are successfully replacing the usual method of the gloved hand for collection of boar ejaculates. These semi-automatic systems require collecting the bulk ejaculate, increasing the proportion of SP in the collected semen samples, and therefore, the putative influence of SP on the capability of boar spermatozoa to withstand the cryopreservation process may be more critical. In addition, it is likely that boar sperm will be held some time surrounded in SP before beginning the freezing process because AI centers are typically located far from the freezing facilities and the time required for ejaculate transport varies. The purpose of this experimental study was to evaluate the influence of native SP, from fractions/portions or 
the entire ejaculate, on boar sperm freezability. Additionally, epididymal sperm were held in SP before freezing for a better understanding of the influence of SP.

\section{Material and methods}

\section{Reagents and Media}

Unless otherwise stated, all of the chemicals used in the experiments were analytical grade and purchased from Sigma-Aldrich Co. (St. Louis, MO, USA). The basic medium used for semen extension was Beltsville Thawing Solution (BTS: composed of $205 \mathrm{mM}$ glucose, $20.4 \mathrm{mM}$ sodium citrate, $10.0 \mathrm{mM} \mathrm{KCl}, 15.0 \mathrm{mM} \mathrm{NaHCO}$, and $3.6 \mathrm{mM}$ EDTA, pH 7.2, and 290-300 mOsmol/kg) supplemented with kanamycin sulfate $(0.05 \mathrm{mM})$. EDTA-free phosphate-buffered saline (PBS; $137 \mathrm{mM} \mathrm{NaCl}, 2.7 \mathrm{mM} \mathrm{KCl}, 1.5 \mathrm{mM}$ $\mathrm{KH}_{2} \mathrm{PO}_{4}, 8.1 \mathrm{mM} \mathrm{Na} \mathrm{HPO}_{4}, \mathrm{pH} 6.8$, and $280-300 \mathrm{mOsmol} / \mathrm{kg}$ ) was used to dilute fluorochromes and extend sperm samples for flow-cytometric analysis. Sperm were frozen using a basic freezing medium (FE) containing $80 \%(\mathrm{v} / \mathrm{v})$ Tris-citric acid-glucose extender (111 mM Trizma Base, $31.4 \mathrm{mM}$ monohydrate citric acid, $185 \mathrm{mM}$ glucose) and $20 \%$ (v/v) egg yolk, supplemented with $100 \mu \mathrm{g} / \mathrm{mL}$ kanamycin sulfate (pH 7.2; 295-300 $\mathrm{mOsmol} / \mathrm{kg})$.

\section{Experimental design}

The experimental design is shown in Figure 1. All of the procedures that involved animals were performed according to international guidelines and were approved by the Bioethics Committee of Murcia University (research code: 639/2012). The boars (Large-White) were three years old, healthy and with a proven history of fertility after conventional AI with liquid semen. At the moment when experiments were drawn, semen was regularly 
collected (twice week) for commercial production of AI-semen doses in a commercial insemination center (AIM Iberica, Calasparra, Murcia, Spain). The boars were, 3-5 days after the month-long experimentation with ejaculates ended, slaughtered at a local slaughterhouse (Mercamurcia, Murcia, Spain). The testes and epididymides from each boar were removed immediately after slaughter and transported in insulated containers at $20-23{ }^{\circ} \mathrm{C}$ to the Andrology Laboratory of Veterinary Teaching Hospital of University of Murcia (VTH), arriving within 30 min after collection.

Ejaculates, bulk or in portions, were collected during the month prior to slaughter using the gloved-hand method and following the standard operating procedure. The portions of ejaculate collected separately were the first $10 \mathrm{~mL}$ of SRF (so-called P1), the remaining SRF (so-called P2) and the PSRF (only as a source of SP as it contained too few sperm). All semen samples from the bulk ejaculate or ejaculate portions met the following criteria: $70 \%$ total motile sperm (subjectively evaluated using light microscopy) and $80 \%$ sperm with normal morphology and intact acrosome ridges (evaluated using phase contrast microscopy of sperm samples fixed in buffered $2 \%$ glutaraldehyde solution). Semen samples were split in two aliquots immediately after collection; one was used for harvesting SP (see below) and the other was extended in pre-warmed $\left(35^{\circ} \mathrm{C}\right) \mathrm{BTS}(2: 1$, $\mathrm{v} / \mathrm{v})$. Thereafter, semen and SP-samples were transported at $20-22{ }^{\circ} \mathrm{C}$ to the Andrology Laboratory of VTH, arriving within $2 \mathrm{~h}$ of collection. Once in the laboratory, the semen samples from bulk ejaculates were split into two aliquots and one was frozen immediately (as Control) whereas the other was stored at $17^{\circ} \mathrm{C}$ during $24 \mathrm{~h}$ before freezing (BE sample). $\mathrm{P} 1$ - and $\mathrm{P} 2$-semen samples were also stored at $17^{\circ} \mathrm{C}$ during $24 \mathrm{~h}$ before freezing. A holding time as long as $24 \mathrm{~h}$ was chosen because it allows any AI center, even those located in remote locations, to ship semen samples overnight to freezing facilities. Also, to hold the semen samples $24 \mathrm{~h}$ before freezing has resulted in high sperm cryosurvival 
rates and excellent fertility outcomes when SRF were frozen using the cryopreservation protocol used in this experiment [16,28].

The SP from each one of SP-sources (first $10 \mathrm{~mL}$ of SRF [SP 1 , rest of SRF [SP 2 and PSRF $\left[\mathrm{SP}_{3}\right]$ ) was harvested via double centrifugation (Rotofix $32 \mathrm{~A}$, Hettich Zentrifugen $^{\circledR}$, Germany) at $1,500 \mathrm{x}$ g for $10 \mathrm{~min}$ at $\mathrm{rt}$. The SP was collected by aspirating fluid above the sperm pellet, preventing disturbance of the pellet. The SP samples were stored at $-80{ }^{\circ} \mathrm{C}$ until used.

Epididymal samples were collected following the procedure described by MartinezPastor et al. [20] with slight modifications. Briefly, the epididymides were removed and dissected avoiding blood contamination. Cauda epididymal luminal fluid was collected by retrograde washing from the vas deferens using a syringe loaded with $1 \mathrm{~mL}$ BTS, injecting air afterwards until all the fluid was flushed out. The harvested caudal epididymal fluids, from both epididymides of the same boar, were collected and mixed in a sterile Petri dish, and the sperm concentration (using an SP-100 NucleoCounter; ChemoMetec A/S, Allerød, Denmark) and motility (see above) was then evaluated. All epididymal samples showed a total sperm motility above 70\%. Epididymal samples were split into three aliquots, extended (to $300 \times 10^{6} \mathrm{sperm} / \mathrm{mL}$ ) with each one of the SPsources, $\mathrm{SP}_{1}$ (EP1 sample), $\mathrm{SP}_{2}\left(\mathrm{EP} 2\right.$ sample) and $\mathrm{SP}_{3}\left(\mathrm{EP} 3\right.$ sample); and stored at $17{ }^{\circ} \mathrm{C}$ during $24 \mathrm{~h}$ before freezing.

\section{Sperm cryopreservation}

The semen samples were centrifuged (Megafuge 1.0 R, Heraeus, Hanau, Germany) at 17 ${ }^{\circ} \mathrm{C}$ for $3 \mathrm{~min}$ at $2400 \mathrm{x} \mathrm{g}$, and the sperm pellets were frozen using the straw freezing procedure described by Hernandez et al. [16]. Briefly, sperm pellets were extended in FE to a concentration of $1.5 \times 10^{9} \mathrm{sperm} / \mathrm{mL}$. After cooling to $5{ }^{\circ} \mathrm{C}$ for $150 \mathrm{~min}$, the sperm 
were re-extended with FE-glycerol-Equex extender (89.5\% FE + 1.5\% Equex STM (v/v) (Nova Chemical Sales, Scituate, MA, USA) and 9\% glycerol (v/v); pH 6.2; 1700-1730 $\mathrm{mOsmol} / \mathrm{kg}$ ) to a final concentration of $1.0 \times 10^{9} \mathrm{sperm} / \mathrm{mL}$. The sperm were thereafter packed into $0.5 \mathrm{ml}$ polyvinyl chloride (PVC) French straws (Minitüb, Tiefenbach, Germany) and frozen using a controlled-rate-freezing machine (IceCube 1810, Minitüb, Germany). The straws remained in liquid nitrogen for at least 1 week before thawing, which was performed in a circulating water bath at $37{ }^{\circ} \mathrm{C}$ for $20 \mathrm{~s}$. The thawed sperm samples were extended in BTS $(1: 1 \mathrm{v} / \mathrm{v})$ and incubated at $37{ }^{\circ} \mathrm{C}$ for up to $300 \mathrm{~min}$.

\section{Assessment of sperm quality and functionality}

The sperm were assessed according to conventional quality parameters (total and progressive motility and viability) and functionality at 30, 150 and $300 \mathrm{~min}$ after thawing in semen samples stored in dark at $37^{\circ} \mathrm{C}$. Functionality was evaluated in terms of plasma membrane fluidity, intracellular $\mathrm{H}_{2} \mathrm{O}_{2}$ (hydrogen peroxide) generation and mitochondrial membrane potential. All of these assessments, except motility, which was evaluated using a computer-assisted sperm analyzer (CASA), were performed using flow cytometry.

Flow cytometric analyses were carried out using a BD FACSCanto II (Becton Dickinson Co, Franklin Lakes, NJ, USA). The optical configuration includes one octagon and two trigon detector arrays. The octagon contains five photomultiplier tubes (PMT) and detects light from the 488-nm (blue) laser. Both trigons contain two PMTs. One detects light from the 633-nm (red) laser and the other detects light from the 633-nm (violet) laser. Data collection and compensation for spectral overlap were performed using BD FACSDiva Software (Becton Dickinson Co). Events were triggered by forward scatter (FSC) and side scatter (SSC) and non-sperm events were gated out based on Hoechst 33342 (H-42) fluorescence (DNA content). Acquisition was stopped after $10000 \mathrm{H}-42$ 
positive events were recorded. The fluorescence spectrum of $\mathrm{H}-42$ was detected using a 450/50 $\mathrm{nm}$ band-pass (BP) filter. The fluorescence spectra of propidium iodide (PI) and fluorescein-conjugated peanut agglutinin (PNA-FITC) were detected using a $670 \mathrm{~nm}$ long-pass (LP) filter and a 530/30 nm BP filter, respectively. The fluorescence spectrum of Merocyanine 540 (M-540) was detected using a 585/42 nm BP filter, and Yo-Pro-1 was detected using a 530/30 $\mathrm{nm}$ BP filter. The fluorescence spectrum of dichlorofluorescein (DCF) was detected using a 530/30 nm BP following excitation at $488 \mathrm{~nm}$. The fluorescence spectrum of Mitotracker Deep Red was detected using a 660/20 BP filter. All fluorescence parameters were log transformed, while FSC and SSC signal were processed in lineal mode.

\section{Sperm motility}

Sperm motility was objectively evaluated using ISASV $1^{\circledR}$ CASA (Proiser R+D, Valencia, Spain) operating up to 100 videoframes/s and following a modification of the procedure described by Cremades et al. [6]. For each evaluation, a $5 \mu \mathrm{L}$ sperm sample $\left(30 \times 10^{6}\right.$ spermatozoa/mL) was placed in a pre-warmed $\left(38^{\circ} \mathrm{C}\right)$ Makler counting chamber (Sefi Medical Instruments, Haifa, Israel), and at least five fields were analyzed to evaluate a minimum of 400 sperm. Sperm motility was recorded as the percentage of total motile sperm (average path velocity $\geq 20 \mu \mathrm{m} / \mathrm{s}$ ) and the percentage of motile sperm showing rapid and progressive movement (straightness of the average path $\geq 40 \%$ ).

\section{Sperm viability}

Sperm viability was evaluated by simultaneously assessing the plasma membrane and acrosome integrity using a triple-fluorescence procedure [19]. Briefly, $100 \mu \mathrm{L}$ aliquots containing $3 \times 10^{6}$ spermatozoa were transferred into culture tubes containing $3 \mu \mathrm{L}$ of $\mathrm{H}$ - 
$42(0.05 \mathrm{mg} / \mathrm{mL}$ in PBS $), 2 \mu \mathrm{L}$ of PI $(0.5 \mathrm{mg} / \mathrm{mL}$ stock solution in PBS $)$, and $2 \mu \mathrm{L}$ of PNA-FITC $(100 \mu \mathrm{g} / \mathrm{mL}$ stock solution in PBS). Samples were mixed and incubated at 37 ${ }^{\circ} \mathrm{C}$ for $10 \mathrm{~min}$ in the dark. Immediately before analysis, $400 \mu \mathrm{L}$ of PBS was added to each sample. The percentage of viable sperm population exhibiting intact plasma and acrosomal membranes (PI negative and PNA-FITC negative) is shown in the Results section.

\section{Plasma membrane fluidity}

The fluidity of the plasma membrane was evaluated by staining sperm with H-42, M-540 and Yo-Pro ${ }^{\circledR}-1$ (Molecular Probes Europe BV, Leiden, The Netherlands). Aliquots of 50 $\mu \mathrm{L}$ of BTS-extended spermatozoa $\left(30 \times 10^{6}\right.$ spermatozoa/mL) were extended in $950 \mu \mathrm{L}$ of PBS containing $1.5 \mu \mathrm{L}$ of $\mathrm{H}-42(0.05 \mathrm{mg} / \mathrm{ml}$ in PBS) and $1 \mu \mathrm{L}$ of Yo-Pro-1 (25 $\mu \mathrm{M}$ in DMSO) and incubated at $38^{\circ} \mathrm{C}$ for $8 \mathrm{~min}$ in the dark. Then, $2.6 \mu \mathrm{L}$ of $\mathrm{M}-540(1 \mathrm{mM}$ in DMSO) was added to each sample, and the samples were incubated for another 2 min under the same conditions before flow cytometric analysis. The sperm Yo-Pro-1 negative and M-540 positive were considered as viable with high plasma membrane fluidity.

\section{Intracellular ROS generation}

The intracellular generation of ROS in viable sperm was measured in terms of hydrogen

peroxide $\left(\mathrm{H}_{2} \mathrm{O}_{2}\right)$ using 5-(and-6) chloromethyl-20,70-dichlorodihydro-fluorescein diacetate acetyl ester (CM- $\mathrm{H}_{2}$ DCFDA) following the procedure described by Guthrie and Welch [13]. For each sperm sample, a $50 \mu \mathrm{L}$ aliquot of BTS-diluted sperm $\left(30 \times 10^{6}\right.$ sperm $/ \mathrm{mL})$ was diluted in $950 \mu \mathrm{L}$ of PBS containing $1.5 \mu \mathrm{L}$ of $\mathrm{H}-42(0.05 \mathrm{mg} / \mathrm{mL}$ in PBS), $1 \mu \mathrm{L}$ of PI ( $1 \mathrm{mg} / \mathrm{mL}$ in PBS), and $1 \mu \mathrm{L}$ of $\mathrm{H}_{2}$ DCFDA ( $1 \mathrm{mM}$ in DMSO) and incubated at $38{ }^{\circ} \mathrm{C}$ for $30 \mathrm{~min}$ in the dark prior to flow cytometric analysis. $\mathrm{H}_{2} \mathrm{DCF}$ is 
oxidized by $\mathrm{H}_{2} \mathrm{O}_{2}$ into DCF. The mean fluorescence intensity of DCF in viable sperm (PI negative) was expressed as fluorescence units (FU) per $10^{8}$ live sperm.

\section{Mitochondrial membrane potential}

The mitochondrial membrane potential was evaluated with Mitotracker Deep Red 633 (Mitotracker, M-22426, Molecular Probes Europe BV) using a variant of protocol described by Domínguez-Rebolledo et al. [10]. Briefly, a $100 \mu \mathrm{L}$ sperm sample (30 x $10^{6}$ sperm/mL in PBS) was transferred to culture tubes containing $3 \mu \mathrm{L} \mathrm{H}-42(0.05 \mathrm{mg} / \mathrm{mL}$ in PBS $), 2 \mu \mathrm{L}$ PI $(0.5 \mathrm{mg} / \mathrm{mL}$ in PBS $)$ and $0.5 \mu \mathrm{L}$ Mitotraker $(20 \mu \mathrm{M}$ in PBS of a stock solution of $1 \mathrm{mM}$ in DMSO). The samples were mixed and incubated at $38{ }^{\circ} \mathrm{C}$ in the dark for $15 \mathrm{~min}$. Immediately before analysis by flow cytometry, $400 \mu \mathrm{L}$ PBS was added to each sample, and the samples were mixed. The percentage of viable sperm (PI negative) with high mitochondria membrane potential (Mitrotraker positive) was reported in the Results section.

\section{Statistical analysis}

Statistical analyses were performed using the SPSS 19 Statistics package (SPSS Inc., Chicago, IL, USA) as follows. The residual data of each sperm quality and functionality variable was evaluated using the Kolmogorov-Smirnov test to confirm the assumption of normality and non-normally distributed data were arcsine transformed before statistical analysis. Data were analyzed using ANOVA procedures with either semen sample or SPsource and post-thaw incubation time (30,150 and $300 \mathrm{~min})$ as the main effects plus their interactions. When the interaction was not significant, it was omitted from the model. Whenever the main effects were significant, means were compared using Bonferroni test. Means of sperm quality and functionality post-thawing of semen and epididymal samples 
were compared by unpaired Student's t test corrected for inequality of variances (Levene's test). Statistical significance was defined as $p<0.05$. Data are shown as the means \pm SEMs.

\section{Results}

Effect of holding time before freezing on the freezability of semen samples

Both semen sample and incubation time after thawing influenced $(\mathrm{p}<0.01)$ post-thaw sperm quality. Sperm quality decreased as post-thaw incubation time increased $(\mathrm{p}<0.01)$. The semen sample $\mathrm{x}$ incubation time interaction was significant $(\mathrm{p}<0.01)$ for total and progressive sperm motility, albeit the four semen samples showed the same pattern in the three post-thaw incubation times (Table 1). Total and progressive sperm motility of P1 and P2 samples were similar and always higher $(\mathrm{p}<0.01)$ than BE samples, regardless of post-thaw incubation time. In addition, sperm motility parameters of P1 were higher ( $\mathrm{p}$ 0.01) than Control at 150 and 300 min post-thawing. Sperm viability of P1 and P2 was higher $(\mathrm{p}<0.01)$ than Control and BE samples, showing the last one the lower $(\mathrm{p}<0.01)$ percentages (Table 1).

The proportion of viable sperm with high plasma membrane fluidity was influenced $(\mathrm{p}<$ 0.01) by semen sample and post-thaw incubation time, whereas the interaction was not significant. The P1 and BE samples showed the lowest $(\mathrm{p}<0.01)$ and highest $(\mathrm{p}<0.01)$ proportions, respectively (Table 1). Semen sample influenced the intracellular generation of $\mathrm{H}_{2} \mathrm{O}_{2}(\mathrm{p}<0.01)$, whereas incubation time did not. The $\mathrm{H}_{2} \mathrm{O}_{2}$ levels generated by $\mathrm{P} 1$ and P2 samples were similar than Control samples and lower $(\mathrm{p}<0.05)$ than BE samples, regardless of the post-thaw incubation time (Table 1). Percentage of viable sperm with high mitochondrial membrane potential was not influenced by semen sample. However, it was influenced by incubation time post-thawing $(\mathrm{p}<0.01)$, decreasing the percentages 
as post-thaw incubation time increased, regardless of the semen samples considered (Table 1).

\section{Influence of SP-source on freezability of epididymal sperm}

SP-source influenced $(\mathrm{p}<0.01)$ total sperm motility and viability after thawing. Postthaw incubation time negatively affected $(\mathrm{p}<0.05)$ motility variables and sperm viability. SP-source $\mathrm{x}$ post-thaw incubation time interaction was not significant for any sperm quality parameter. The EP1 and EP2 samples showed higher $(\mathrm{p}<0.001)$ percentages of total motility than EP3 samples. The EP1 and EP3 samples showed the highest $(\mathrm{p}<0.01)$ and lowest $(\mathrm{p}<0.01)$ percentages of viable sperm (Table 2$)$.

SP-source did not influence the proportion of viable sperm with both high plasma membrane fluidity and high mitochondrial membrane potential, whereas their post-thaw incubation time did $(\mathrm{p}<0.01)$. SP-source $\mathrm{x}$ post-thaw incubation time interaction was not significant for both functionality parameters. The percentages of viable sperm with high plasma membrane fluidity increased whereas those with high mitochondrial membrane potential decreased with incubation time (Table 2). The intracellular generation of $\mathrm{H}_{2} \mathrm{O}_{2}$ in viable sperm was influenced $(\mathrm{p}<0.05)$ by SP-source and incubation time, being not significant the interaction. The generation of $\mathrm{H}_{2} \mathrm{O}_{2}$ increased during incubation in all epididymal sperm samples, showing EP1 and EP2 samples lower $(\mathrm{p}<0.05)$ generation than EP3 samples (Table 2).

\section{Sperm freezability differences between semen and epididymal samples}

Post-thaw sperm quality, in terms of motility parameters and viability, was lower ( $\mathrm{p}<$ 0.05) in ejaculates than in epididymal samples throughout the three post-thawing incubation times (Table 3). Regarding post-thaw functionality of viable sperm (Table 3), 
the percentage of those cells with high plasma membrane fluidity just differed between BE and EP3 samples, showing BE samples the highest $(\mathrm{p}<0.05)$ percentage in all postthaw incubation times. The intracellular $\mathrm{H}_{2} \mathrm{O}_{2}$ generation was higher $(\mathrm{p}<0.05)$ in semen than in epididymal samples at 30 min; and only in BE samples than EP3 samples at 150 min. The percentage of sperm with high mitochondrial membrane potential was lower ( $p$ $<0.05)$ in semen compared to epididymal samples throughout all post-thaw incubation times.

\section{Discussion}

From a practical point of view, semen samples for freezing should withstand a holding time of several hours at cooling temperatures before freezing because AI-centers, where ejaculates are collected, are often away from freezing facilities. In this sense, $24 \mathrm{~h}$ seems a holding time sufficiently long for any AI centers, even those located in remote locations, to ship semen samples for freezing. This long holding time, already incorporated in some cryopreservation protocols, has proven to be effective since it allows achieving acceptable cryosurvival rates and fertility outcomes when held semen samples were of SRF origin [12]. Results from our laboratory, achieving cryosurvival rates above $80 \%$ [18] and fertility outcomes as high as $85.6 \%$ of farrowing rates and 12.6 piglets born per litter [28], support the effectiveness of $24 \mathrm{~h}$ of holding time to cryopreserve semen samples from SRF. Recently has been corroborated the suitability of a holding time of $24 \mathrm{~h}$ before freezing to improve cryotolerance of boar SRF-sperm [37].

However, the scenario we are confronted now is whether this long holding time before freezing would also be effective to cryopreserve spermatozoa collected from the bulk ejaculate, instead than being those fortuitously present in the SRF. To contemplate this 
scenario is now mandatory since AI-centers are incorporating semiautomatic systems for ejaculate collection that do not allow to collect separate ejaculate fractions. The results of the present study clearly demonstrated that a holding time before freezing as long as $24 \mathrm{~h}$ impairs sperm freezability of spermatozoa retrieved from a bulk ejaculate. Moreover, this study also shows that sperm from the SRF withstands cryopreservation better than those from the bulk ejaculate when semen samples were held $24 \mathrm{~h}$ before freezing. Putative freezability differences between sperm from the SRF or the BE have not been comparatively evaluated previously. Instead, some previous studies have focused on evaluating differences between first $10 \mathrm{~mL}$ of SRF and rest of ejaculate, showing that sperm from the first withstands cryopreservation better than sperm from latter fractions $[22,23,32]$. These studies, that contemplate a holding time before freezing of only $2 \mathrm{~h}$, found that the differences were particularly evident for sperm motility and not in all boars. Aware of these studies, semen samples from the first $10 \mathrm{ml}$ of SRF were included in the present experiment and they were also held during $24 \mathrm{~h}$ before freezing. Cryosurvival rates and functionality of alive sperm from the first $10 \mathrm{ml}$ of the SRF were similar to those from of rest of SRF, which was in agreement with previous results [34], but, as noticeably and in contrast to the above studies, clearly better of those from the BE. So, it seems that extending the holding time before freezing from 2 to $24 \mathrm{~h}$ makes differences in sperm freezability between SRF (including the first $10 \mathrm{~mL}$ ) and bulk ejaculate become more apparent. The differences, evaluated in FT-sperm incubated over $300 \mathrm{~min}$, were not only clearly evident in classical quality parameters, such as motility and viability, but also in some functionality sperm parameters, specifically plasma membrane fluidity and intracellular generation of $\mathrm{H}_{2} \mathrm{O}_{2}$, both being higher in the viable FT-sperm from the bulk ejaculate than those from both first $10 \mathrm{~mL}$ of SRF and rest SRF. This functional differences are particularly noticeable because a greater fluidity of plasma membrane 
together with a higher endogenous generation of $\mathrm{H}_{2} \mathrm{O}_{2}$, the primary ROS generated by boar spermatozoa [1], are events exhibited by boar sperm exposed to capacitation conditions [19]. Thus, it seems that FT-sperm of semen samples held $24 \mathrm{~h}$ before freezing from bulk ejaculate are more sensitive to premature capacitation than those from SRF, including its first $10 \mathrm{~mL}$ (peak-sperm portion). The differences in sperm cryosurvival and functionality evidenced between SRF (including the peak-sperm portion) and BE should be attributed to the composition of SP surrounding the sperm during the holding time. Certainly, differences in either SP proteins or bicarbonate concentration among ejaculate portions have been shown responsible for differences in post-thaw sperm functionality [32]. From the present results, it seems that the SP from the entire ejaculate is less cryoprotective than that from the SRF alone (including the peak-portion). Moreover, semen samples held long time before freezing surrounded in the SP of the entire ejaculate deteriorate during cryosurvival, perhaps due to a negative influence of the PSRF that counteracts the cryoprotective effects of SP from SRF (including first $10 \mathrm{~mL}$ ).

To test the above hypothesis, samples collected from the epididymides of the same boars were held $24 \mathrm{~h}$ extended in SP from the three portions of the ejaculate (peak-sperm portion, rest of the SRF and from the PSRF). Cryosurvival rates of epididymal samples held in SP either the sperm-peak portion or the rest of the SRF were similar, mimicking results achieved with comparative ejaculated semen samples, but were better than sperm exposed to PSRF. In addition, sperm held in SP either the sperm-peak portion or the rest of the SRF generate less $\mathrm{H}_{2} \mathrm{O}_{2}$ than those exposed to PSRF. Overall, the results show that indeed the SP from PSRF is less sperm-cryoprotective than SP from SRF, which might be attributable to its higher levels of bicarbonate (and a more alkaline $\mathrm{pH}$ ) [33], low concentrations of chemicals with antioxidant capacity [3] and highest content in HBPs proteins that under in vitro conditions failed to preserve the sperm viability and 
functionality [5]. However, given these peculiarities in the composition of SP of PSRF and looking at the above results achieved with ejaculated sperm, a greater loss in postthaw quality and functionality in the epididymal sperm held diluted in SP from PSRF was expected. The differences in both the quality and the post-thaw sperm function observed between the epididymis and ejaculated samples could give an explanation for this unexpected finding. Since we did not test sperm from PSRF (owing to the very low sperm numbers present), we compared the epididymal sperm held diluted in SP from PSRF and those exposed to that from entire ejaculate. Epididymal sperm always showed better postthaw quality and functionality than those ejaculated, regardless of the ejaculate portion from which they came or the SP-source used to held epididymal sperm before freezing. Then, it is clear that epididymal sperm are more cryoresilient that ejaculated sperm, which was in agreement with previous report [25], which is attributed the protective effect of epididymal fluid, containing low bicarbonate levels and absence of relative high levels of proteins [7 and references therein,29]. Probably this greater protection of epididymal fluid explains why epididymal sperm withstood cryopreservation better irrespective of the exposure to PS from either PSRF or entire ejaculate.

In conclusion, our results showed that boar sperm from bulk ejaculate are more cryosensitive than those from the sperm rich ejaculate fraction, particularly when held 24 $\mathrm{h}$ before freezing surrounded by their own seminal plasma, which would be attributable to the effects exerted by the seminal plasma on sperm during the holding time. This evidence challenges the suitability of the collection of bulk ejaculates instead the hitherto usual sperm rich ejaculate fraction for cryopreservation, especially if semen samples must be hold some time before freezing to be shipped from a place to another for freezing. Although further fertility trials are needed to confirm in the farm the practical relevance of these results, they seem conclusive enough to recommend to AI-centers to continue 
collecting rich ejaculate fraction instead of bulk ejaculate for sperm cryopreservation. Otherwise, the sperm cryopreservation procedure should be modified if the collection of bulk ejaculates is mandatory.

\section{Conflict of interest}

The authors declare that there is no conflict of interest that could prejudice the impartiality of this paper.

\section{Acknowledgments}

D. V. Alkmin, C. Perez-Patiño and I. Barranco was financially supported by the Science Without Borders program (Brazilian Scientific Mobility Program at CNPq/MCT), Seneca Foundation (Murcia, Spain) and MECD (Madrid, Spain), respectively. The authors are grateful to AIM Iberica for supplying the boar ejaculates. This experimental study was supported by MINECO (AGL2012-39903) Madrid (Spain), FEDER funds and by Formas, Stockholm, Sweden.

\section{References}

[1] B.J. Awda, M. Mackenzie-Bell, M.M. Buhr, Reactive oxygen species and boar sperm function, Biol. Reprod. 81 (2009) 553-561.

[2] S.B. Barrabes Aneas, B.G. Gary, B.P. Bouvier, Collectis ${ }^{\circledR}$ automated boar collection technology, Theriogenology 70 (2008) 1368-1373. 
[3] I. Barranco, A. Tvarijonaviciute, C. Perez-Patiño, D.V. Alkmin, J.J. Ceron, E.A. Martinez, J.Roca, Paraoxonase type-1 in boar seminal plasma, Reprod. Dom. Anim. 48 (2013) 91.

[4] E. Breininger, A. Descalzo, L. Rossetti, D. Abramovich, M.T. Beconi, Boar sperm functionality is related to $\alpha$-tocopherol content after freezing-thawing, Andrologia 43 (2011) 409-415.

[5] F. Centurión, J.M. Vazquez, J.J. Calvete, J. Roca, L. Sanz, I. Parrilla, E.M. Garcia, E.A. Martinez, Influence of porcine spermadhesins on the susceptibility of boar spermatozoa to high dilution, Biol. Reprod. 69 (2003) 640-646.

[6] T. Cremades, J. Roca, H. Rodriguez-Martinez, T. Abaigar, J.M. Vazquez, E.A. Martinez, Kinematic changes during the cryopreservation of boar spermatozoa, J. Androl. 26 (2005) 610-618.

[7] J.L. Dacheux, F. Dacheux, New insights into epididymal function in relation to sperm maturation, Reproduction 147 (2014) R27-R42.

[8] S.P. de Graaf, T. Leahy, J. Marti, G. Evans, W.M. Maxwell, Application of seminal plasma in sex-sorting and sperm cryopreservation, Theriogenology 70 (2008) 1360-1363.

[9] B.A. Didion, G.D. Braun, M.V. Duggan, Field fertility of frozen boar semen: A retrospective report comprising over 2600 AI services spanning a four year period, Anim. Reprod. Sci. 137 (2013) 189-196. 
[10] A.E. Domínguez-Rebolledo, M.R. Fernández-Santos, O. García-Alvarez, A. Maroto-Morales, J.J. Garde, F. Martínez-Pastor, Washing increases the susceptibility to exogenous oxidative stress in red deer spermatozoa, Theriogenology 72 (2009) 1073-84.

[11] B.M. Eriksson, J.M. Vázquez, E.A. Martínez, J. Roca, X. Lucas, H. RodríguezMartínez, Effects of holding time during cooling and of type of package on plasma membrane integrity, motility and in vitro oocyte penetration ability of frozen thawed boar spermatozoa, Theriogenology 55 (2001) 1593-1605.

[12] H.D. Guthrie, G.R. Welch, Impact of storage prior to cryopreservation on plasma membrane function and fertility of boar sperm, Theriogenology 63 (2005) 396-410.

[13] H.D. Guthrie, G.R. Welch, Determination of intracellular reactive oxygen species and high mitochondrial membrane potential in Percoll-treated viable boar sperm using fluorescence-activated flow cytometry, J. Anim. Sci. 84 (2006) 2089-2100.

[14] O. Gutiérrez-Pérez, M.D.L. Juárez-Mosqueda, S.U. Carvajal, M.E.T. Ortega, Boar spermatozoa cryopreservation in low glycerol/trehalose enriched freezing media improves cellular integrity, Cryobiology 58 (2009) 287-292.

[15] M. Hernandez, J. Roca, J.J. Calvete, L. Sanz, T. Muiño-Blanco, J.A. Cebrian-Perez, J.M. Vazquez, E.A. Martinez, Cryosurvival and in vitro fertilizing capacity postthaw is improved when boar spermatozoa are frozen in the presence of seminal plasma from good freezer boars, J. Androl. 28 (2007) 689-697. 
[16] M. Hernandez, J. Roca, M.A. Gil, J.M. Vazquez, E.A. Martinez, Adjustments on the cryopreservation conditions reduce the incidence of boar ejaculates with poor sperm freezability, Theriogenology 67 (2007) 1436-1445.

[17] J.H. Hu, Q.W. Li, Z.L. Jiang, W.Y. Li, Effects of different extenders on DNA integrity of boar spermatozoa following freezing-thawing, Cryobiology 57 (2008) 257262.

[18] J.D. Juarez, I. Parrilla, J.M. Vazquez, E.A. Martinez, J. Roca, Boar semen can tolerate rapid cooling rates prior to freezing, Reprod. Fertil. Dev. 23 (2011) 681-690.

[19] M.J. Martinez-Alborcia, A. Valverde, I. Parrilla, J.M. Vazquez, E.A. Martinez, J. Roca, Detrimental effects of non-functional spermatozoa on the freezability of functional spermatozoa from boar ejaculate, PLoS One 7 (2012) e36550.

[20] F. Martinez-Pastor, V. Garcia-Macias, M. Alvarez, C. Chamorro, P. Herraez, P.D. Paz, L. Anel, Comparison of two methods for obtaining spermatozoa from the cauda epididymis of Iberian red deer, Theriogenology 65 (2006) 471-485.

[21] T. Okazaki, S. Abe, S. Yoshida, M. Shimada, Seminal plasma damages sperm during cryopreservation, but its presence during thawing improves semen quality and conception rates in boars with poor post-thaw semen quality, Theriogenology 71 (2009) 491-498. 
[22] F.J. Peña, A. Johannisson, M. Wallgren, H. Rodríguez-Martínez, Antioxidant supplementation in vitro improves boar sperm motility and mitochondrial membrane potential after cryopreservation of different fractions of the ejaculate, Anim. Reprod. Sci. 78 (2003) 85-98.

[23] F.J. Peña, A. Johannisson, M. Wallgren, H. Rodríguez-Martinez, Antioxidant supplementation of boar spermatozoa from different fractions of the ejaculate improves cryopreservation: changes in sperm membrane lipid architecture, Zygote 12 (2004) 117124.

[24] V.G. Pursel, S.A. Johnson, L.L. Shuman, Effect of dilution, seminal plasma and incubation period on cold shock susceptibility of boar spermatozoa, J. Anim. Sci. 37 (1973) 532-535.

[25] D. Rath, H. Niemann, In vitro fertilization of porcine oocytes with fresh and frozenthawed ejaculated or frozen-thawed epididymal semen obtained from identical boars, Theriogenology 47 (1997) 785-793.

[26] D. Rath, R. Bathgate, H. Rodriguez-Martinez, J. Roca, J. Strzezek, D. Waberski, Recent advances in boar semen cryopreservation, Soc. Reprod. Fertil. Suppl. 66 (2009) 51-66.

[27] J.M. Ringwelski, J.E. Beever, R.V. Knox, Effect of interval between inseminations when using frozen-thawed boar sperm on fertility and fetal paternity in mature gilts, Anim. Reprod. Sci. 137 (2013) 197-204. 
[28] J. Roca, I. Parrilla, H. Rodriguez-Martinez, M.A. Gil, C. Cuello, J.M. Vazquez, E.A. Martinez, Approaches towards efficient use of boar semen in the pig industry, Reprod. Dom. Anim. 46 (2011) 79-83.

[29] H. Rodriguez-Martinez, U. Kvist, F. Saravia, M. Wallgren, A. Johannisson, L. Sanz, J.J Calvete, The physiological roles of the boar ejaculate, Soc. Reprod. Fertil. Suppl. 66 (2009) 1-21.

[30] H. Rodriguez-Martinez, U. Kvist, J. Ernerudh, L. Sanz, J.J. Calvete, Seminal plasma proteins: what role do they play?, Am. J. Reprod. Immunol. 66 (2011) 11-22.

[31] F. Saravia, M. Wallgren, S. Nagy, A. Johannisson, H. Rodríguez-Martínez, Deep freezing of concentrated boar semen for intra-uterine insemination: effects on sperm viability, Theriogenology 63 (2005) 1320-1333.

[32] F. Saravia, M. Wallgren, A. Johannisson, J.J. Calvete, L. Sanz, F.J. Pena, H. Rodriguez-Martinez, Exposure to the seminal plasma of different portions of the boar ejaculate modulates the survival of spermatozoa cryopreserved in MiniFlatPacks, Theriogenology 71 (2009) 662-675.

[33] F. Saravia, M. Wallgren, H. Rodríguez-Martínez, Freezing of boar semen can be simplified by handling a specific portion of the ejaculate with a shorter procedure and MiniFlatPack packaging, Anim. Reprod. Sci. 117 (2010) 279-87. 
[34] A.P. Siqueira, M. Wallgren, M.S. Hossain, A. Johannisson, L. Sanz, J.J. Calvete, H. Rodriguez-Martinez, Quality of boar spermatozoa from the sperm-peak portion of the ejaculate after simplified freezing in MiniFlatpacks compared to the remaining spermatozoa of the sperm-rich fraction, Theriogenology 75 (2011) 1175-1184.

[35] C. Tomás, J. Gómez-Fernández, E. Gómez-Izquierdo, E. de Mercado, Effect of the holding time at $15{ }^{\circ} \mathrm{C}$ prior to cryopreservation, the thawing rate and the post-thaw incubation temperature on the boar sperm quality after cryopreservation, Anim. Reprod. Sci. 144 (2014) 115-121.

[36] M.L. Vadnais, G.C. Althouse, Characterization of capacitation, cryoinjury, and the role of seminal plasma in porcine sperm, Theriogenology 76 (2011) 1508-1516.

[37] M. Yeste, E. Estrada, M.M. Rivera Del Álamo, S. Bonet, T. Rigau, J.E. RodríguezGil, The increase in phosphorylation levels of serine residues of protein HSP70 during holding time at $17{ }^{\circ} \mathrm{C}$ is concomitant with a higher cryotolerance of boar spermatozoa, PLoS One 9 (2014) e90887. 


\section{Figure legend:}

Figure 1. Schematic view of the experimental design showing how the semen samples from ejaculates and epididymides were handled.

\section{Tables:}

Table 1. Differences (mean \pm SEM) in freezability among semen samples $(n=10)$ from bulk ejaculate (BE), the first $10 \mathrm{~mL}$ of sperm rich ejaculate fraction $(\mathrm{P} 1)$ and the rest of sperm rich ejaculate fraction $(\mathrm{P} 2)$ held at $15-17^{\circ} \mathrm{C}$ during $24 \mathrm{~h}$ before freezing surrounded in their own seminal plasma. Semen samples from entire ejaculate frozen immediately after collection were used as Control.

\begin{tabular}{cccccc}
\hline Sperm parameters (\%) & Semen & \multicolumn{2}{c}{ Post-thawing incubation time (min) } & \\
\cline { 3 - 5 } & Samples & $\mathbf{3 0}$ & $\mathbf{1 5 0}$ & $\mathbf{3 0 0}$ & mean \\
\hline Total sperm motility & Control & $55.1 \pm 2.0^{\mathrm{a} \alpha}$ & $36.1 \pm 2.6^{\mathrm{b} \beta}$ & $9.1 \pm 1.4^{\mathrm{bc} \gamma}$ & $33.4 \pm 3.7$ \\
& $\mathrm{BE}$ & $42.8 \pm 2.1^{\mathrm{b} \alpha}$ & $26.6 \pm 1.9^{\mathrm{c} \beta}$ & $5.5 \pm 0.6^{\mathrm{c} \gamma}$ & $25.0 \pm 3.0$ \\
& $\mathrm{P} 1$ & $61.6 \pm 1.7^{\mathrm{a} \alpha}$ & $44.9 \pm 1.6^{\mathrm{a} \beta}$ & $13.6 \pm 1.7^{\mathrm{a} \gamma}$ & $40.1 \pm 2.8$ \\
& $\mathrm{P} 2$ & $57.7 \pm 1.9^{\mathrm{a} \alpha}$ & $42.0 \pm 1.8^{\mathrm{ab} \beta}$ & $10.4 \pm 0.9^{\mathrm{ab} \gamma}$ & $36.7 \pm 2.7$ \\
& mean & $56.1 \pm 1.3$ & $39.4 \pm 1.3$ & $10.5 \pm 0.8$ & \\
Progressive sperm & Control & $41.5 \pm 0.5^{\mathrm{a} \alpha}$ & $28.2 \pm 1.8^{\mathrm{b} \beta}$ & $5.8 \pm 0.7^{\mathrm{bc \gamma}}$ & $25.3 \pm 2.8$ \\
motility & $\mathrm{BE}$ & $25.9 \pm 1.0^{\mathrm{b} \alpha}$ & $19.0 \pm 1.0^{\mathrm{c} \beta}$ & $3.7 \pm 0.5^{\mathrm{c \gamma}}$ & $16.2 \pm 1.8$ \\
& $\mathrm{P} 1$ & $43.8 \pm 1.5^{\mathrm{a} \alpha}$ & $34.4 \pm 1.6^{\mathrm{a} \beta}$ & $9.4 \pm 1.1^{\mathrm{a} \gamma}$ & $29.2 \pm 2.1$ \\
& $\mathrm{P} 2$ & $41.8 \pm 1.5^{\mathrm{a} \alpha}$ & $30.9 \pm 1.3^{\mathrm{ab} \beta}$ & $7.6 \pm 0.7^{\mathrm{ab} \gamma}$ & $26.8 \pm 2.0$ \\
Sperm viability & mean & $39.9 \pm 1.1$ & $29.6 \pm 1.1$ & $7.2 \pm 0.5$ & \\
& Control & $50.3 \pm 1.2$ & $47.1 \pm 0.2$ & $38.2 \pm 1.0$ & $45.2 \pm 1.1^{\mathrm{b}}$ \\
& $\mathrm{BE}$ & $40.8 \pm 2.1$ & $37.9 \pm 1.9$ & $30.2 \pm 1.7$ & $36.3 \pm 1.4^{\mathrm{c}}$ \\
& $\mathrm{P} 1$ & $61.0 \pm 2.0$ & $52.2 \pm 2.1$ & $42.0 \pm 1.8$ & $51.7 \pm 1.5^{\mathrm{a}}$ \\
& $\mathrm{P} 2$ & $57.6 \pm 1.7$ & $50.3 \pm 1.4$ & $40.4 \pm 1.4$ & $49.4 \pm 1.3^{\mathrm{a}}$ \\
\hline High plasma & mean & $54.7 \pm 1.3^{\alpha}$ & $48.3 \pm 1.1^{\beta}$ & $38.9 \pm 1.0^{\gamma}$ & \\
membrane & Control & $4.6 \pm 0.3$ & $6.7 \pm 0.4$ & $9.4 \pm 0.5$ & $6.9 \pm 0.4^{\mathrm{a}}$ \\
& $\mathrm{BE}$ & $8.2 \pm 0.5$ & $10.3 \pm 0.6$ & $13.7 \pm 0.6$ & $10.7 \pm 0.5^{\mathrm{c}}$ \\
\hline
\end{tabular}




\begin{tabular}{cccccc}
\hline fluidity & P1 & $2.6 \pm 0.3$ & $6.0 \pm 0.4$ & $8.8 \pm 0.6$ & $5.8 \pm 0.4^{\mathrm{b}}$ \\
& $\mathrm{P} 2$ & $3.8 \pm 0.3$ & $6.2 \pm 0.4$ & $9.2 \pm 0.5$ & $6.7 \pm 0.4^{\mathrm{a}}$ \\
\hline Intracellular & mean & $4.3 \pm 0.3^{\alpha}$ & $6.9 \pm 0.3^{\beta}$ & $10.2 \pm 0.4^{\gamma}$ & \\
H2O2 generation $_{\text {(FU x 108/sperm) }}$ & Control & $27.8 \pm 2.1$ & $28.3 \pm 2.0$ & $28.3 \pm 1.4$ & $28.1 \pm 1.1^{\mathrm{a}}$ \\
& $\mathrm{BE}$ & $30.9 \pm 1.9$ & $31.4 \pm 1.3$ & $32.0 \pm 1.1$ & $31.4 \pm 0.8^{\mathrm{b}}$ \\
& $\mathrm{P} 1$ & $25.4 \pm 1.3$ & $27.1 \pm 2.1$ & $27.3 \pm 1.3$ & $26.6 \pm 0.9^{\mathrm{a}}$ \\
& $\mathrm{P} 2$ & $25.7 \pm 1.4$ & $25.3 \pm 1.4$ & $25.7 \pm 1.1$ & $25.6 \pm 0.8^{\mathrm{a}}$ \\
\hline High mitochondrial & mean & $27.5 \pm 0.8$ & $28.0 \pm 1.0$ & $28.3 \pm 0.7$ & \\
membrane potential & Control & $47.5 \pm 0.6$ & $46.7 \pm 0.6$ & $30.6 \pm 2.1$ & $41.6 \pm 1.6$ \\
& $\mathrm{BE}$ & $49.3 \pm 0.8$ & $48.7 \pm 0.5$ & $33.3 \pm 2.3$ & $43.8 \pm 1.6$ \\
& $\mathrm{P} 1$ & $50.9 \pm 0.7$ & $46.4 \pm 0.8$ & $31.8 \pm 1.3$ & $43.0 \pm 1.2$ \\
& $\mathrm{P} 2$ & $49.3 \pm 0.5$ & $45.4 \pm 0.9$ & $32.5 \pm 1.9$ & $42.4 \pm 1.2$ \\
\hline
\end{tabular}

FU: fluorescence units. a-c: indicate differences $(\mathrm{p}<0.05)$ among semen samples (rows); $\alpha, \beta, \gamma$ : indicate differences $(\mathrm{p}<0.05)$ among incubation times (columns).

Table 2. Differences (mean \pm SEM) in freezability among epididymal sperm samples extended in seminal plasma collected from either the first $10 \mathrm{~mL}$ of sperm rich ejaculate fraction (EP1), the rest of sperm rich ejaculate fraction (EP2) or the post sperm rich ejaculate fraction (EP3), and held at $15-17^{\circ} \mathrm{C}$ during $24 \mathrm{~h}$ before freezing.

\begin{tabular}{|c|c|c|c|c|c|}
\hline \multirow{2}{*}{$\begin{array}{c}\text { Sperm } \\
\text { parameters }(\%)\end{array}$} & \multirow{2}{*}{$\begin{array}{l}\text { Epididymal } \\
\text { Samples }\end{array}$} & \multicolumn{3}{|c|}{ Post-thawing incubation time (min) } & \multirow[b]{2}{*}{ mean } \\
\hline & & 30 & 150 & 300 & \\
\hline \multirow{4}{*}{$\begin{array}{l}\text { Total sperm } \\
\text { motility }\end{array}$} & EP1 & $72.1 \pm 1.3$ & $57.0 \pm 2.2$ & $44.1 \pm 1.8$ & $57.7 \pm 2.4^{\mathrm{a}}$ \\
\hline & EP2 & $70.8 \pm 1.8$ & $56.8 \pm 2.0$ & $42.8 \pm 1.9$ & $56.8 \pm 2.4^{\mathrm{a}}$ \\
\hline & EP3 & $66.1 \pm 1.6$ & $55.2 \pm 1.5$ & $40.5 \pm 2.4$ & $53.9 \pm 2.2^{b}$ \\
\hline & mean & $69.7 \pm 1.0^{\alpha}$ & $56.3 \pm 1.1^{\beta}$ & $42.5 \pm 1.2^{\gamma}$ & \\
\hline \multirow{4}{*}{$\begin{array}{c}\text { Progressive sperm } \\
\text { motility }\end{array}$} & EP1 & $51.4 \pm 1.5$ & $43.2 \pm 1.0$ & $32.1 \pm 0.9$ & $42.2 \pm 1.6$ \\
\hline & EP2 & $52.1 \pm 1.8$ & $41.6 \pm 0.7$ & $31.5 \pm 1.1$ & $41.7 \pm 1.7$ \\
\hline & EP3 & $48.9 \pm 1.7$ & $42.4 \pm 1.4$ & $29.5 \pm 2.0$ & $40.3 \pm 1.8$ \\
\hline & mean & $50.8 \pm 1.0^{\alpha}$ & $42.4 \pm 0.6^{\beta}$ & $31.0 \pm 0.8^{\gamma}$ & \\
\hline \multirow{4}{*}{ Sperm viability } & EP1 & $66.2 \pm 1.0$ & $57.5 \pm 1.8$ & $51.2 \pm 1.3$ & $58.3 \pm 1.4^{\mathrm{a}}$ \\
\hline & EP2 & $62.3 \pm 1.1$ & $56.6 \pm 1.9$ & $48.5 \pm 0.8$ & $55.8 \pm 1.3^{b}$ \\
\hline & EP3 & $59.6 \pm 1.8$ & $53.9 \pm 2.1$ & $44.8 \pm 1.8$ & $52.8 \pm 1.6^{\mathrm{c}}$ \\
\hline & mean & $62.7 \pm 0.9^{\alpha}$ & $56.0 \pm 1.1^{\beta}$ & $48.2 \pm 0.9^{\gamma}$ & \\
\hline \multirow{4}{*}{$\begin{array}{c}\text { High plasma } \\
\text { membrane } \\
\text { fluidity }\end{array}$} & EP1 & $3.6 \pm 0.4$ & $6.9 \pm 0.7$ & $9.4 \pm 0.9$ & $6.7 \pm 0.6$ \\
\hline & EP2 & $3.6 \pm 0.4$ & $6.4 \pm 0.7$ & $9.0 \pm 0.6$ & $6.3 \pm 0.5$ \\
\hline & EP3 & $4.1 \pm 0.4$ & $6.6 \pm 0.5$ & $9.6 \pm 0.9$ & $6.8 \pm 0.5$ \\
\hline & mean & $3.8 \pm 0.2^{\alpha}$ & $6.6 \pm 0.4^{\beta}$ & $9.3 \pm 0.5^{\gamma}$ & \\
\hline \multirow{4}{*}{$\begin{array}{c}\text { Intracellular } \\
\mathrm{H}_{2} \mathrm{O}_{2} \text { generation } \\
\left(\text { FU x 10 } \text { 10 }^{8}\right)\end{array}$} & EP1 & $18.9 \pm 1.1$ & $23.9 \pm 1.4$ & $27.3 \pm 1.7$ & $23.4 \pm 1.0^{\mathrm{b}}$ \\
\hline & EP2 & $18.8 \pm 1.5$ & $23.9 \pm 2.0$ & $27.4 \pm 1.7$ & $23.4 \pm 1.2^{b}$ \\
\hline & EP3 & $21.3 \pm 1.4$ & $24.9 \pm 1.6$ & $29.6 \pm 2.4$ & $25.3 \pm 1.2^{\mathrm{a}}$ \\
\hline & mean & $19.6 \pm 0.8^{\alpha}$ & $24.2 \pm 0.9^{\beta}$ & $28.1 \pm 1.1^{\gamma}$ & \\
\hline \multirow{2}{*}{$\begin{array}{l}\text { High mitochondrial } \\
\text { membrane potential }\end{array}$} & EP1 & $54.4 \pm 0.4$ & $50.7 \pm 1.3$ & $42.7 \pm 0.7$ & $49.3 \pm 1.0$ \\
\hline & EP2 & $53.1 \pm 0.7$ & $49.4 \pm 1.3$ & $42.8 \pm 0.9$ & $48.4 \pm 1.0$ \\
\hline
\end{tabular}




\begin{tabular}{cccccc}
\hline & EP3 & $55.4 \pm 0.4$ & $48.7 \pm 1.8$ & $41.7 \pm 1.1$ & $48.6 \pm 1.2$ \\
& mean & $54.3 \pm 0.3^{\alpha}$ & $49.6 \pm 0.8^{\beta}$ & $42.4 \pm 0.5^{\gamma}$ & \\
\hline
\end{tabular}

FU: fluorescence units. a-c: indicate differences $(\mathrm{p}<0.05)$ among epididymal samples (rows); $\alpha, \beta, \gamma$ : indicate differences $(\mathrm{p}<0.05)$ among incubation times (columns).

Table 3: Differences in sperm freezability in terms of quality and functionality between semen and epididymal samples at 30, 150 and 300 min post-thawing.

\begin{tabular}{|c|c|c|c|c|c|c|c|c|}
\hline \multirow[b]{2}{*}{$\begin{array}{l}\text { Incubation } \\
\text { time (min) }\end{array}$} & \multirow[b]{2}{*}{$\begin{array}{c}\text { SP } \\
\text { source }\end{array}$} & \multirow[b]{2}{*}{$\begin{array}{l}\text { Sperm } \\
\text { source }\end{array}$} & \multicolumn{3}{|c|}{ Sperm quality } & \multicolumn{3}{|c|}{ Sperm functionality } \\
\hline & & & $\begin{array}{c}\text { Total } \\
\text { motility (\%) }\end{array}$ & $\begin{array}{l}\text { Progressive } \\
\text { motility (\%) }\end{array}$ & Viability (\%) & $\begin{array}{l}\text { High } \\
\text { plasma } \\
\text { membrane } \\
\text { fluidity (\%) }\end{array}$ & $\begin{array}{c}\mathrm{H}_{2} \mathrm{O}_{2} \\
\text { generation } \\
\left(\text { FU x 10 } 10^{8} \text { ) }\right.\end{array}$ & $\begin{array}{c}\text { High } \\
\text { mitochondrial } \\
\text { membrane } \\
\text { potential }(\%)\end{array}$ \\
\hline \multirow{6}{*}{30} & \multirow{2}{*}{$\mathrm{SP}_{1}$} & Ejaculate & $61.4 \pm 2.4^{\mathrm{b}}$ & $43.8 \pm 2.1^{\mathrm{b}}$ & $60.9 \pm 2.0^{\mathrm{b}}$ & $2.6 \pm 0.3$ & $25.4 \pm 1.3^{\mathrm{a}}$ & $50.9 \pm 0.7^{b}$ \\
\hline & & Epididymis & $71.1 \pm 1.9^{\mathrm{a}}$ & $51.0 \pm 1.7^{\mathrm{a}}$ & $66.2 \pm 1.0^{\mathrm{a}}$ & $3.6 \pm 0.4$ & $19.3 \pm 1.3^{\mathrm{b}}$ & $54.4 \pm 0.4^{\mathrm{a}}$ \\
\hline & \multirow{2}{*}{$\mathrm{SP}_{2}$} & Ejaculate & $57.7 \pm 2.4^{\mathrm{b}}$ & $41.7 \pm 2.1^{\mathrm{b}}$ & $57.6 \pm 1.7^{\mathrm{b}}$ & $3.8 \pm 0.3$ & $25.7 \pm 1.4^{\mathrm{a}}$ & $49.3 \pm 0.5^{\mathrm{b}}$ \\
\hline & & Epididymis & $71.0 \pm 2.2^{\mathrm{a}}$ & $52.1 \pm 2.5^{\mathrm{a}}$ & $62.4 \pm 1.2^{\mathrm{a}}$ & $3.6 \pm 0.4$ & $18.8 \pm 1.5^{\mathrm{b}}$ & $53.1 \pm 0.7^{\mathrm{a}}$ \\
\hline & \multirow{2}{*}{$\mathrm{SP}_{3}$} & Ejaculate & $42.8 \pm 3.1^{\mathrm{b}}$ & $25.9 \pm 1.1^{\mathrm{b}}$ & $40.8 \pm 2.1^{\mathrm{b}}$ & $8.2 \pm 0.5^{\mathrm{a}}$ & $30.9 \pm 1.9^{\mathrm{a}}$ & $49.3 \pm 0.8^{b}$ \\
\hline & & Epididymis & $66.1 \pm 2.5^{\mathrm{a}}$ & $48.9 \pm 1.7^{\mathrm{a}}$ & $59.6 \pm 1.8^{\mathrm{a}}$ & $4.1 \pm 0.4^{b}$ & $21.3 \pm 1.4^{b}$ & $55.4 \pm 0.4^{\mathrm{a}}$ \\
\hline \multirow{6}{*}{150} & \multirow{2}{*}{$\mathrm{SP}_{1}$} & Ejaculate & $44.9 \pm 2.2^{b}$ & $34.4 \pm 2.0^{b}$ & $52.2 \pm 2.1$ & $5.9 \pm 0.4$ & $27.2 \pm 2.1$ & $46.4 \pm 0.8^{b}$ \\
\hline & & Epididymis & $57.0 \pm 2.7^{\mathrm{a}}$ & $43.1 \pm 1.7^{\mathrm{a}}$ & $57.5 \pm 1.8$ & $6.9 \pm 0.7$ & $24.4 \pm 1.7$ & $50.7 \pm 1.3^{\mathrm{a}}$ \\
\hline & \multirow{2}{*}{$\mathrm{SP}_{2}$} & Ejaculate & $42.0 \pm 1.8^{\mathrm{b}}$ & $30.9 \pm 1.6^{\mathrm{b}}$ & $50.3 \pm 1.4^{b}$ & $6.2 \pm 0.4$ & $25.3 \pm 1.4$ & $45.4 \pm 0.9^{b}$ \\
\hline & & Epididymis & $56.8 \pm 2.9^{\mathrm{a}}$ & $41.6 \pm 1.0^{\mathrm{a}}$ & $56.6 \pm 1.9^{\mathrm{a}}$ & $6.4 \pm 0.7$ & $23.9 \pm 2.0$ & $49.4 \pm 1.3^{\mathrm{a}}$ \\
\hline & \multirow{2}{*}{$\mathrm{SP}_{3}$} & Ejaculate & $26.6 \pm 1.9^{b}$ & $19.0 \pm 1.6^{\mathrm{b}}$ & $37.9 \pm 1.9^{b}$ & $10.3 \pm 0.6^{\mathrm{a}}$ & $31.4 \pm 1.3^{\mathrm{a}}$ & $48.7 \pm 0.5$ \\
\hline & & Epididymis & $55.2 \pm 2.1^{\mathrm{a}}$ & $42.4 \pm 1.8^{\mathrm{a}}$ & $53.9 \pm 2.1^{\mathrm{a}}$ & $6.6 \pm 0.5^{b}$ & $24.9 \pm 1.6^{\mathrm{b}}$ & $48.7 \pm 1.8$ \\
\hline \multirow{6}{*}{300} & \multirow{2}{*}{$\mathrm{SP}_{1}$} & Ejaculate & $13.7 \pm 1.9^{b}$ & $9.4 \pm 1.4^{b}$ & $42.0 \pm 1.8^{\mathrm{b}}$ & $8.8 \pm 0.6$ & $27.3 \pm 1.3$ & $31.8 \pm 1.3^{b}$ \\
\hline & & Epididymis & $44.1 \pm 2.7^{\mathrm{a}}$ & $32.1 \pm 1.4^{\mathrm{a}}$ & $51.2 \pm 1.3^{\mathrm{a}}$ & $9.4 \pm 0.9$ & $27.3 \pm 1.7$ & $42.7 \pm 0.7^{\mathrm{a}}$ \\
\hline & \multirow{2}{*}{$\mathrm{SP}_{2}$} & Ejaculate & $10.5 \pm 1.3^{\mathrm{b}}$ & $7.6 \pm 1.1^{b}$ & $40.4 \pm 1.4^{b}$ & $10.2 \pm 0.5$ & $25.7 \pm 1.1$ & $32.5 \pm 1.9^{b}$ \\
\hline & & Epididymis & $42.8 \pm 2.3^{\mathrm{a}}$ & $31.5 \pm 1.6^{\mathrm{a}}$ & $48.5 \pm 0.8^{\mathrm{a}}$ & $8.9 \pm 0.6$ & $27.4 \pm 1.7$ & $42.8 \pm 0.9^{\mathrm{a}}$ \\
\hline & \multirow{2}{*}{$\mathrm{SP}_{3}$} & Ejaculate & $5.5 \pm 0.9^{b}$ & $3.7 \pm 0.5^{b}$ & $30.2 \pm 1.7^{b}$ & $13.7 \pm 0.6^{\mathrm{a}}$ & $30.9 \pm 1.2$ & $33.3 \pm 2.3^{b}$ \\
\hline & & Epididymis & $40.7 \pm 3.1^{\mathrm{a}}$ & $29.5 \pm 2.3^{\mathrm{a}}$ & $44.8 \pm 1.8^{\mathrm{a}}$ & $9.6 \pm 0.9^{b}$ & $29.6 \pm 2.4$ & $41.7 \pm 1.1^{\mathrm{a}}$ \\
\hline
\end{tabular}

a,b: indicate differences $(\mathrm{p}<0.05)$ between sperm source within each SP source and incubation time. 


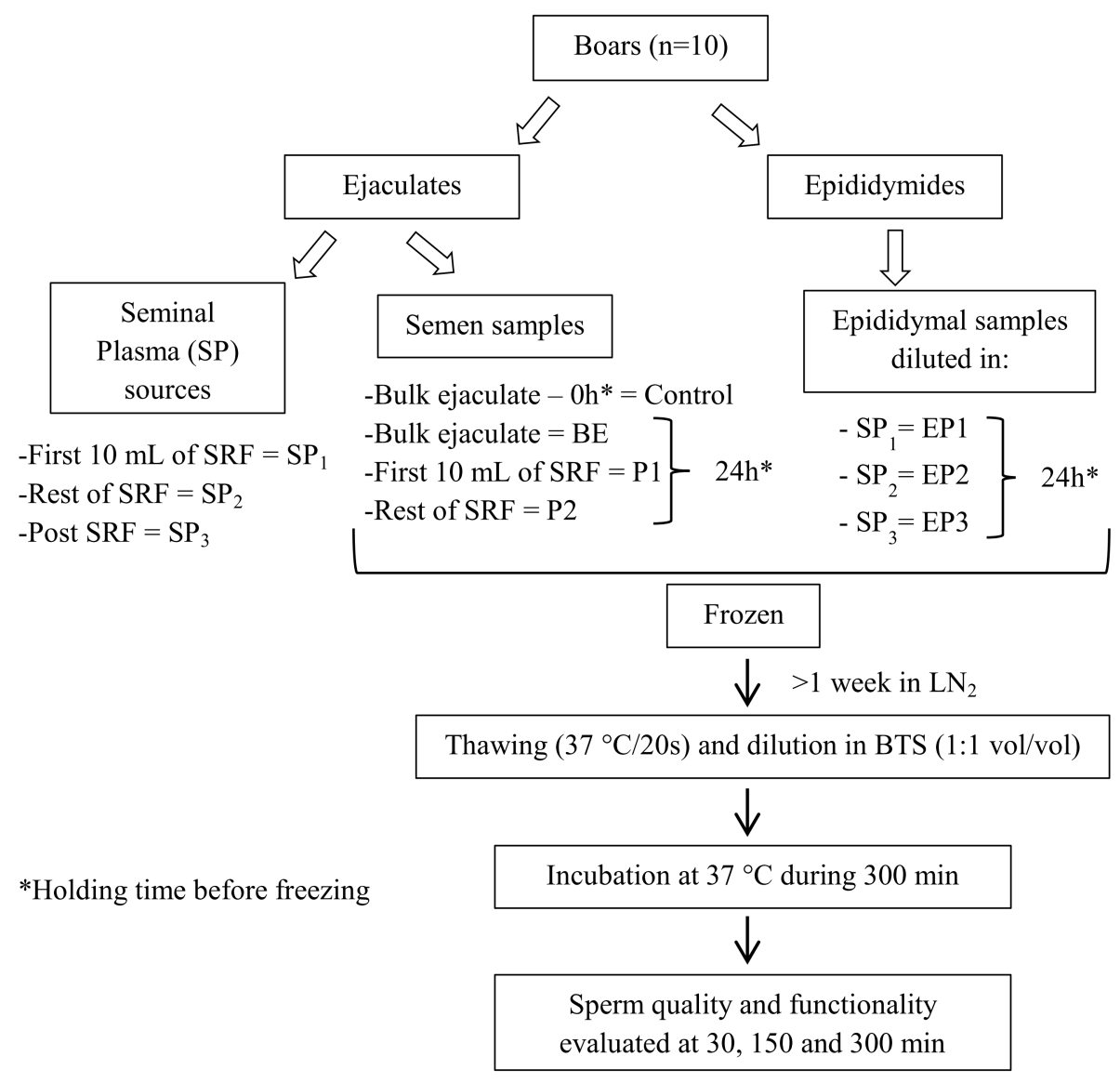



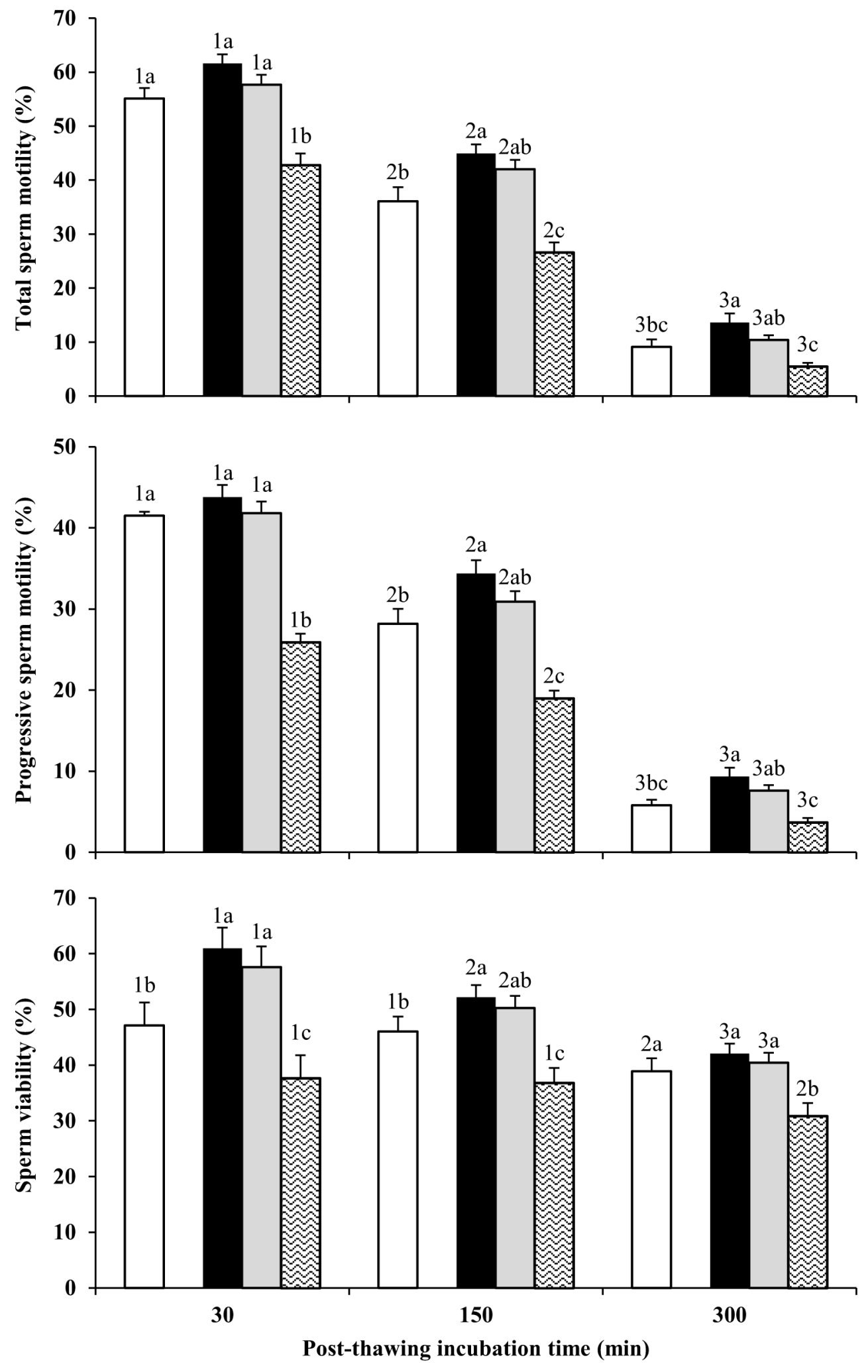
口Control $\square \mathrm{P} 1 \quad \square \mathrm{P} 2$ 固EE
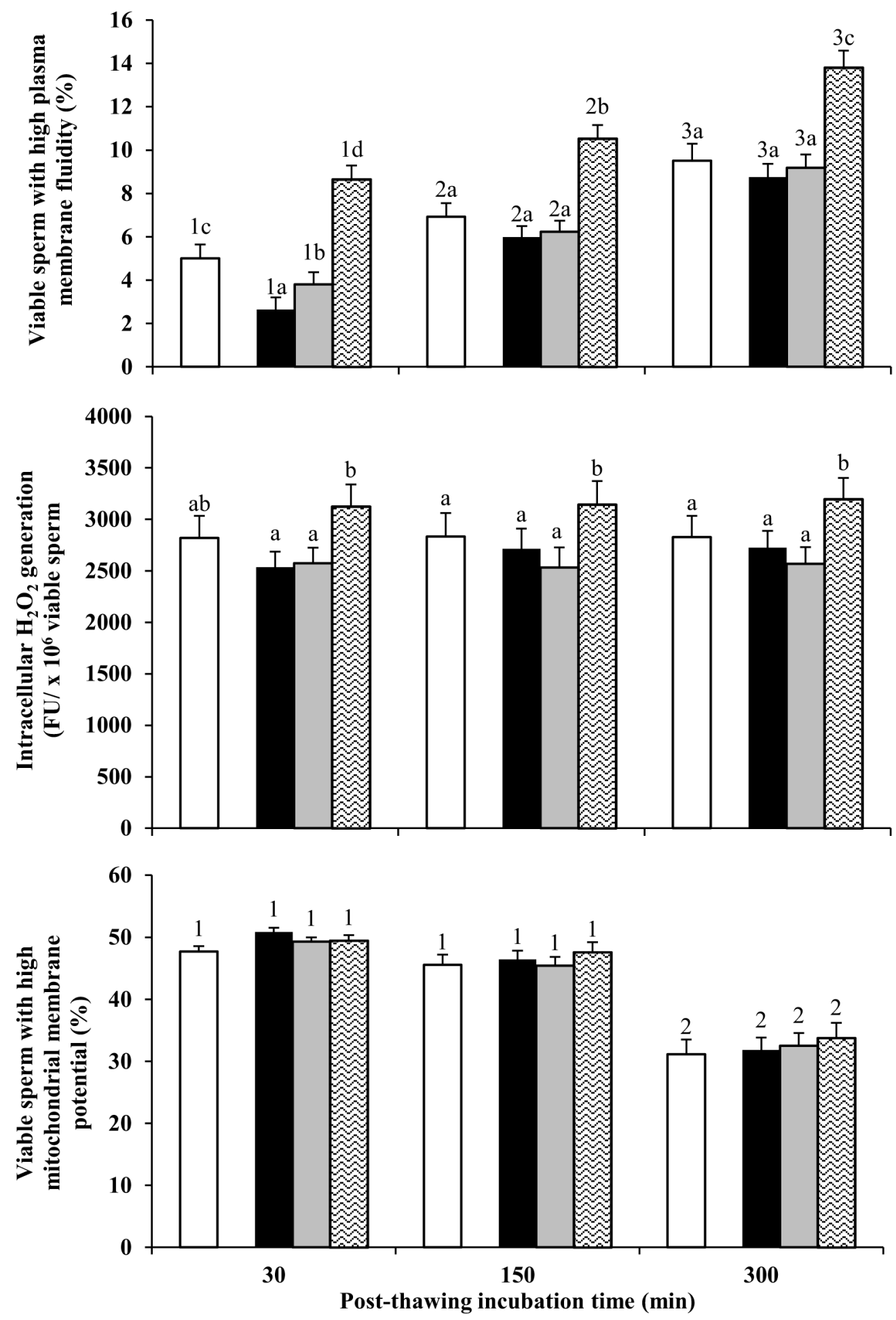
-EP1 口EP2 बEP3
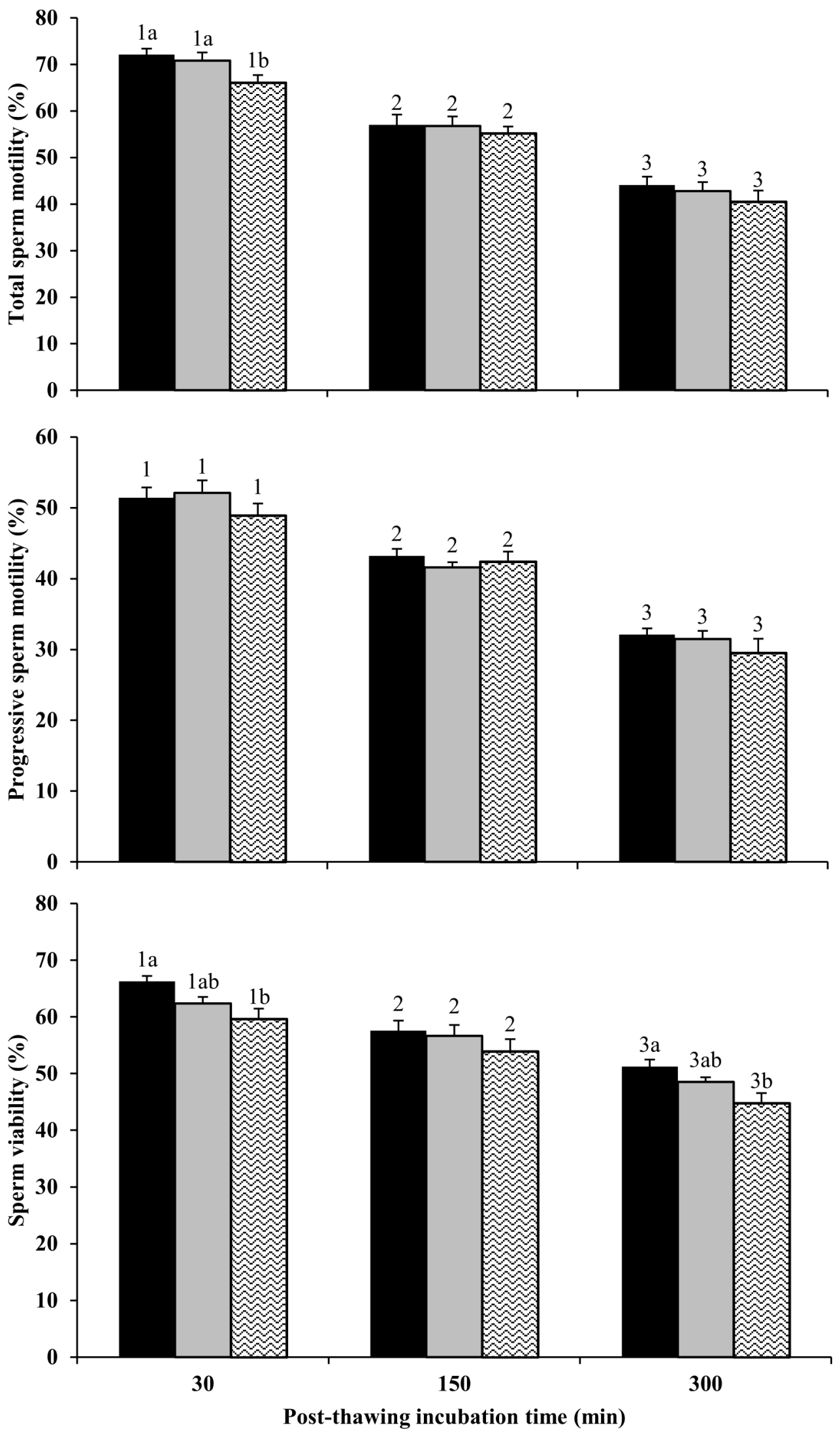
-EP1 口EP2 $\mathrm{E}$ EP3
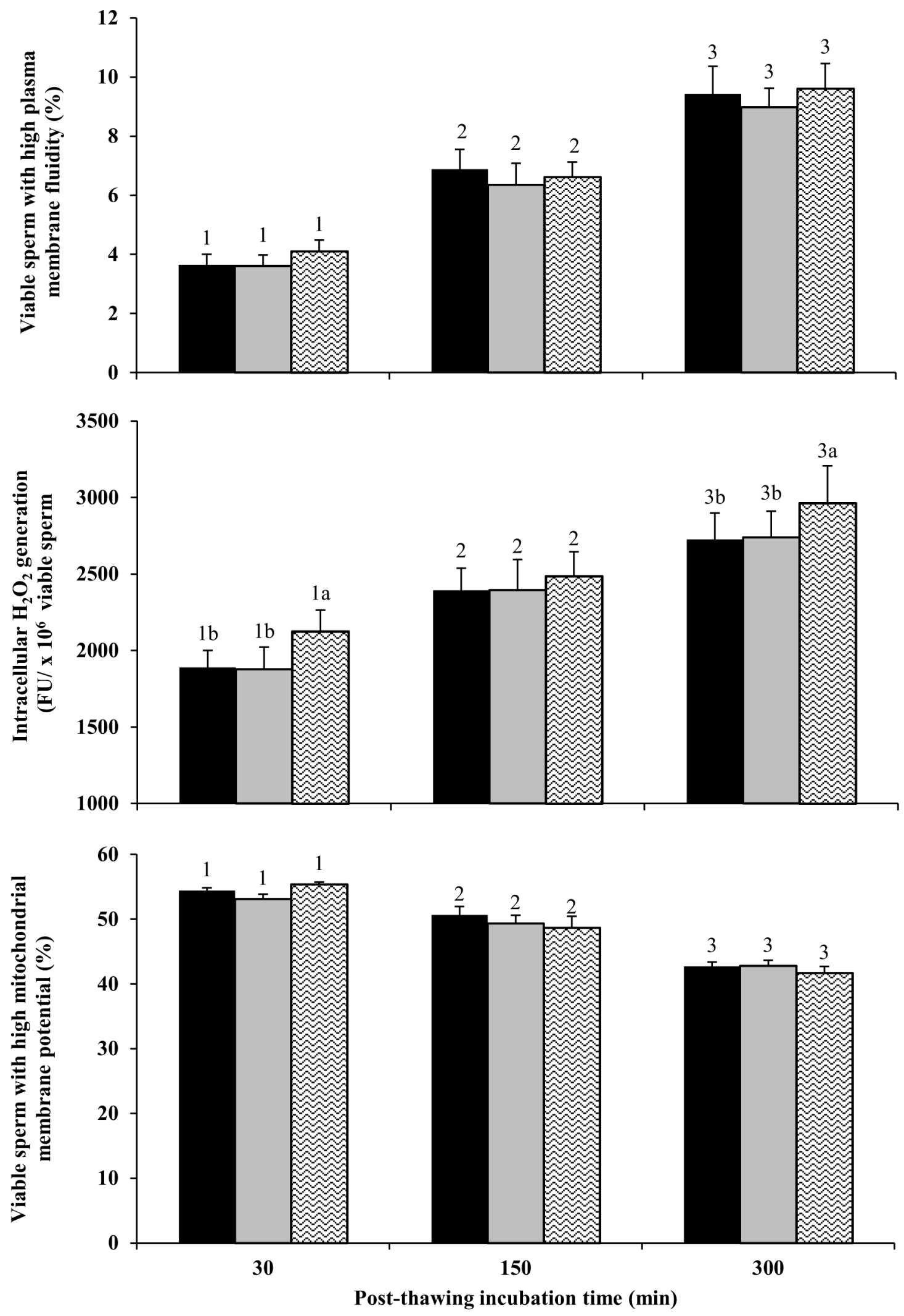